\title{
The possible mechanisms of CYP2E1 interactions with HSP90 and the influence of ethanol on them
}

\author{
Volodymyr O Kitam*, Oksana V Maksymchuk ${ }^{\dagger}$ and Mykola O Chashchyn ${ }^{\dagger}$
}

\begin{abstract}
Background: Microsomal CYP2E1 metabolizes about 160 hydrophobic exogens, many of which are environmental pollutants. While metabolising xenobiotics CYP2E1 on one hand facilitates in their excretion and on the other hand activates them into the cytotoxins, which may damage the cell. Thus the CYP2E1 activity level significantly affects the processes in cell. Posttranslational stabilization of CYP2E1 seems to be the main mechanism of its regulation in living cell. It is known that degradation of CYP2El takes part in cytoplasmic proteasome system. The efficiency of such degradation depends on the presence of molecular chaperones (HSP90) as was shown from in vitro experiments. But the processes that involve HSP90 in the degradation of CYP2E1 and the mechanisms of transfer of microsomal CYP2E1 to the proteasome system remain unknown. This paper investigates HSP90-dependent processes in mechanisms of CYP2El degradation and the possible role of ethanol in them.

Results: With the help of computational methods we have shown that CYP2E1 can interact with HSP90 resulting in dissociation of CYP2E1 from membrane and formation of the CYP2E1-HSP90 complex for its further transfer to the proteasome for degradation. The twofold increase of both CYP2E1 and HSP90 in the mouse liver under the constant alcohol administration was shown using WB methods. Also, as was shown in silico, ethanol molecule, while binding to the CYP2E1 active site, prevents its interaction with HSP90, thus resulting in accumulation of CYP2E1 in cell.

Conclusions: Cytoplasmic HSP90 and membrane-bound CYP2E1 may directly interact with each other as partner proteins, leading to the dissociation of the CYP2E1 from the membrane. This makes it possible to transfer microsomal CYP2E1 in complex with HSP90 to the proteasome for proteolysis. The ethanol molecule inhibits the interaction of HSP90 with CYP2E1 leading to the suppression of its proteasome degradation, thus increasing level of this protein in the cell. Other substrates of CYP2E1 should increase level of this protein in the same way. This may be one of the mechanisms of substrate-dependent regulation of the CYP2E1 expression in the cell.
\end{abstract}

\section{Background}

As the main role of microsomal CYP2E1 is detoxification of xenobiotics (exogenous low weight compounds) the highest level of its constitutive expression is found in liver and kidneys, organs that mostly utilize and excrete harmful substances off the organism [1,2]. There are 160 hydrophobic substances of exogenous origin known as substrates for CYP2E1 (http://cpd.ibmh.msk.su/). Most of them are environmental pollutants (industrial wastes, fertilizers and solvents), components of food additives, drugs and cosmetics. CYP2E1 on one hand contributes in withdrawal of xenobiotics by metabolizing them in liver (thus taking

\footnotetext{
* Correspondence: v.o.kitam@gmail.com

${ }^{\dagger}$ Equal contributors

Institute of molecular biology and genetics of NAS of Ukraine, Kyiv, Ukraine
}

active part in adaptation of organism to the adverse environmental factors). On the other hand CYP2E1, while metabolizing, may activate its substrates into cytotoxins, which causes different cell damages. Substrates of CYP2E1 induce its protein expression level but the mechanisms of such induction steel need to be investigated. Such increase in CYP2E1 protein level causes homeostasis misbalance in cell. Thus it is shown that introduction of ethanol (one of the most widely used CYP2E1 substrate) into the animals causes intensification of peroxidation processes and depletion of hepatocyte antioxidant system [3]. Activation of peroxidation processes may be caused by the ethanoldependent induction of CYP2E1, which can generate oxygen radicals during its catalytic cycle. As a result an oxidation stress usually develops in cell [4]. Herewith ethanol 
does not only stimulate CYP2E1-dependent peroxidation, but serves as a source of free radicals itself (during the CYP2E1-dependent oxidation of ethanol a 1-hydroxyethyl radical is being formed $[3,5]$ ). Posttranslational stabilization of protein molecule with substrates is one of the main mechanisms of regulation of CYP2E1 expression level in cell. It is believed that substrates while in the active site of enzyme, change and stabilize protein structure, thus preventing its fast degradation with proteasomes[6-8]. The mechanisms of such substrates-dependent CYP2E1 protein stabilization mostly are staying uninvestigated. The processes of transfer of microsomal CYP2E1 to the proteasome (where its degradation takes place) also need to be investigated. It is thought that cytoplasm heat shock proteins, in particular HSP90, actively participate in these processes [9-11]. This work is devoted to investigating the role of HSP90 in the degradation of microsomal CYP2E1 and studying the influence of ethanol on these processes.

\section{Results and discussion}

It is known that the level of CYP2E1 expression in cell is regulated at all stages of protein biosynthesis from the initiation of transcription to the posttranslational stabilization of this enzyme [12]. Posttranslational substrate-dependent stabilization is one of the main mechanisms that regulates the intracellular content of CYP2E1 [12,13]. It is shown that the stabilization of CYP2E1 by the ethanol molecule increases its half-life period from 6 to 37 hours [7]. It is known that in the absence of substrate and with the participation of the enzymes of proteasome system the socalled rapid degradation of CYP2E1 is taking place. The in vitro experiments with heterologous recombinant proteins revealed that a cytoplasmic heat shock proteins could play a decisive role in the mechanisms of such degradation
[11]. In particular, it was shown that specific inhibition of HSP90 resulted in the accumulation of microsomal CYP2E1 in cell $[9,10]$. However, HSP90-dependent processes of CYP2E1 degradation are poorly investigated today. It is also unclear how CYP2E1 is being transferred from membrane to the cytoplasm and becomes accessible to the proteasome degradation system. In order to investigate the HSP90-dependent processes in the CYP2E1 degradation mechanisms we have evaluated the possibility of direct spatial interactions of proteins by using computer simulation methods. During the protein-protein docking of CYP2E1 with HSP90 the CYP2E1-HSP90 complex was obtained. This complex (Figure 1A) is characterized in the Table 1. Due to this model, it was revealed that HSP90 binds to membrane-associated domain of CYP2E1 (the main external functionally active sites in the structure of CYP2E1 are presented in Table 2). Besides, two main structural and functional features of this complex could be distinguished from Tables 1 and 2. First of all, the entrance to the CYP2E1 active centre channel is being covered by HSP90 molecule, which reduces the probability of CYP2E1 interaction with substrates. This prevents protein structure stabilization by substrates and results in enzyme rapid degradation. Secondly, some hydrophobic region of CYP2E1 (primarily amino acid residues responsible for the association with the membrane) is also being screened by HSP90 molecule while forming CYP2E1-HSP90 complex. This promotes the microsomal CYP2E1 dissociation from the membrane and helps to shuttle it into the cytoplasm to the proteasome for proteolysis. The obtained results that allowed us to evaluate the studied proteins as partners confirmed data obtained by other authors during in vitro experiments with heterologous recombinant proteins [11]. It is known that substrate-dependent stabilization of the

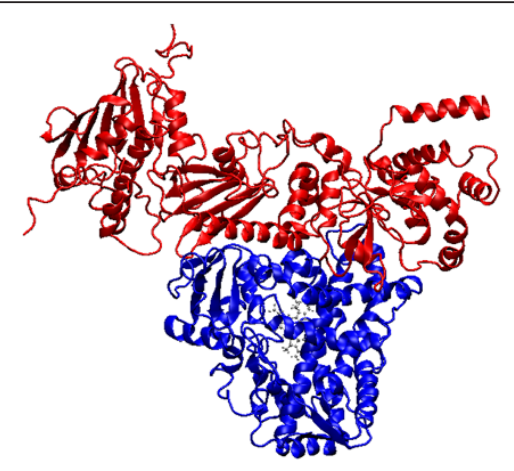

A

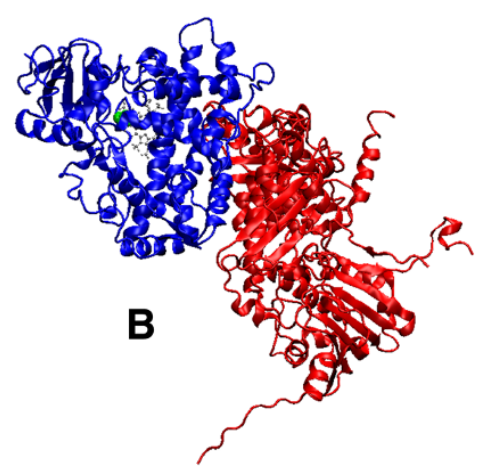

Figure 1 Complexes of HSP90 with CYP2E1 (A) and CYP2E1-ethanol (B). CYP2E1 is colored in blue and HSP90 - in red, ethanol molecule is shown as green spheres and heme molecule is shown as gray ball-and-stick. 
Table 1 The main characteristics of HSP90 complexes with CYP2E1 and CYP2E1-ethanol

\begin{tabular}{|c|c|c|}
\hline Parameters & CYP2E1-HSP90 & CYP2E1-ethanol-HSP90 \\
\hline $\begin{array}{l}\text { Binding energy } \\
\left(-\Delta \mathrm{G}_{\mathrm{Gibbs}} \mathrm{K} / \text { mole }\right)\end{array}$ & 800 & 470 \\
\hline Contact area $(\AA 22)$ & 1941 & 1010 \\
\hline $\begin{array}{l}\text { Resides of CYP2E1 } \\
\text { involved in contact } \\
\text { with HSP90 }\end{array}$ & $\begin{array}{l}\text { L32, F37, P38, P40, I41, Y71, S74, Q75, R76, D102, P104, H107, } \\
\text { A108, H109, R110, D111, R112, G119, P120, T121, R198, Y218, } \\
\text { P222, S223, L225, H226, I236, H232, R233, K237, A240, E241, } \\
\text { K243, E244, Y245, S247, E248, K251, A280, E281, M286, D287, } \\
\text { T290, V291, R374, D375, L382, K385, G386 (49) }\end{array}$ & $\begin{array}{l}\text { N135, Y136, G139, K140, Q141, G142, E144, S145, Q148, } \\
\text { R149, H152, F153, E156, R159, K160, Q162, K187, S336, R337, } \\
\text { I338, A340, P491 (22) }\end{array}$ \\
\hline
\end{tabular}

CYP2E1 molecule significantly inhibits its degradation [6]. It was shown that ethanol can structurally stabilize the CYP2E1 molecule and suppress proteolysis by the ethanol-dependent inhibition of the proteolytic system [8]. However, the mechanism of such an inhibition has not been fully understood yet. During our work the features of CYP2E1 and HSP90 expression under the chronic action of ethanol were studied. WB method revealed a twofold increase in CYP2E1 level in the liver of experimental mice, which consumed 10\% ethanol in drinking water for 35 days (Figure 2A). Previously, no significant changes were shown in Cyp2e1 mRNA level relative to the control under similar experimental conditions [14]. The obtained data indicates that the increase in CYP2E1 protein level is caused by the stabilization of the enzyme molecule but not by the transcription process intensification. It is known that such substrate-dependent induction of CYP2E1 increases peroxidation processes and leads to the antioxidant system depletion and development of oxidative stress in the cell. This state is accompanied by intracellular structural and functional damages of macromolecules (such as denaturation, degradation, protein misfolding, etc.), thus in turn causing an intensification of the stress genes expression, in particular genes that encode proteins of the HSP family. The doubling of HSP90 content in the liver of experimental animals was found using WB method (Figure 2B). Such increase in intracellular stress proteins level is one of the main adaptive responses to oxidative stress and is aimed to restore the cell homeostasis [15]. The increase in the level of expression of the HSP90 should lead to the intensification of CYP2E1 proteolysis and reducing of its content in the cell. However, such effect was not observed in our experimental conditions. Therefore, we suggested that under the chronic effect of ethanol the interaction of the chaperone HSP90 with CYP2E1 is being inhibited thus blocking its HSP90- mediated transfer to the proteasome for subsequent degradation. In order to test this hypothesis we studied the effect of ethanol on the interactions of CYP2E1 with HSP90. For this purpose, a complex of CYP2E1 with ethanol (CYP2E1-ethanol) was designed and optimized using computer simulation methods. We have shown that ethanol molecule causes some decrease in volume and surface area of the CYP2E1 (Table 3). This may indicate the spatial stabilization of CYP2E1 molecule. Some changes in charges on protein surface and a significant decrease in the enzyme polar surface under the influence of ethanol were also shown (Table 3). The appearance of large positively charged region in the area of entrance to the active site and changes in the CYP2E1 protein surface charge and polar surface area can affect its ability to interact with other ligands and/or protein partners, HSP90 in particular. To study the effect of ethanol on the CYP2E1 interaction with HSP90, we performed a protein-protein docking of CYP2E1-ethanol with HSP90. The structure of CYP2E1ethanol-HSP90 complex is presented at Figure 1B. The obtained data showed significant change in preferred HSP90 binding site of CYP2E1 (the detailed characteristics of CYP2E1-ethanol-HSP90 complex are presented in Methods section). Such difference in favourable binding sites may be explained by the changes in charged regions on protein surface in presence of ethanol. The obtained data shows that some structural adjustments in spatial structure of CYP2E1 under the influence of ethanol reduce the efficiency of its interaction with HSP90. Such ethanoldependent inhibition of the CYP2E1-HSP90 complex formation leads to further inhibition of both the enzyme dissociation from the membrane and its subsequent degradation in the proteasome. This may explain the revealed elevation of CYP2E1 level in conjunction with a high level of HSP90 expression in the liver of animals chronically treated with ethanol. Based on these results we can assume

Table 2 The main domains and functionally active sites in the structure of CYP2E1

\begin{tabular}{ll}
\hline & Localization (residue number from N-term) \\
\hline Membrane-associated domain & $1-96,368-390$ \\
Cytoplasmic domain & $97-367,391-491$ \\
Active site and its channel & $41-57,70-79,113-119,202-218,298-305,387-396,467-471$ \\
\hline
\end{tabular}


that the cytoplasmic HSP90 and microsomal CYP2E1, as partner proteins, can directly interact with each other leading to the dissociation of the CYP2E1 from the membrane and its further transfer to the proteasome for proteolysis. The ethanol-dependent inhibition of the interaction between HSP90 and CYP2E1 suppresses its proteasome degradation, thus leading to its accumulation in the cell. The obtained data let us suggest that this is one of the mechanisms of substrate-dependent regulation of the CYP2E1 level in the cell.

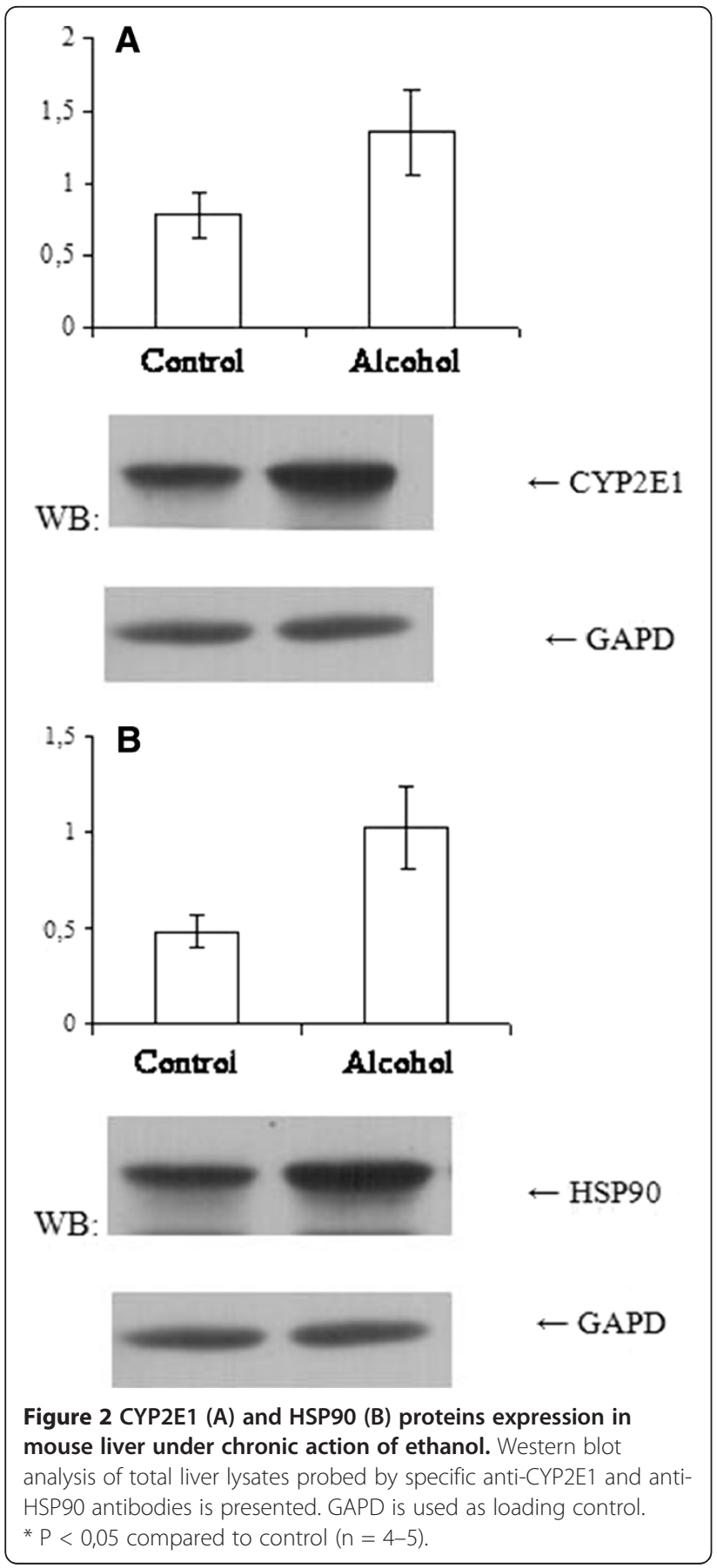

\section{Conclusions}

Cytoplasmic chaperone HSP90 and membrane-bound CYP2E1, as partner proteins may directly interact with each other, leading to the dissociation of the CYP2E1 from the membrane. This makes it possible to transfer microsomal CYP2E1 to the proteasome for proteolysis. The ethanol molecule inhibits the interaction of HSP90 with CYP2E1 leading to the increased content of this protein in the cell. We assume that other substrates of CYP2E1 should increase its content in the same way. This may be one of the mechanisms of substrate-dependent regulation of the CYP2E1 level in the cell.

\section{Methods}

\section{Animals}

The Institute of Molecular Biology and Genetics Bioethics Committee (head Prof. Dr. Lukash LL) according to the "Recommendations of the ethics committees that carry out the examination of biomedical research" (WHO, 2000), the order of the AMS of Ukraine № 50 from 06.07.2001 "On establishment of committees of medical ethics in research institutions of Academy of Sciences of Ukraine" and the "General ethical principles of animal experiments" (1 National Congress on Bioethics, Kyiv, 2001) approved procedures involved in the breeding and handling of animals (protocol № 10 dated 24.09.2008).

We used BALB/C mouse males, 3.5 months old, with the average weight of $30 \mathrm{~g}$ from vivarium of the Institute of Molecular Biology and Genetics of the National Academy of Sciences of Ukraine (Kyiv) in our work. Mice were kept at standard conditions with inverted diurnal light regime (8 night hours), at temperature $18-20^{\circ} \mathrm{C}$ and on standard diet. Animals were divided into two groups: experimental and control (intact). The experimental mice were fed with $10 \%$ ethanol in water. On day 35 mice of both groups were decapitated under the light ether anaesthesia.

\section{Western blotting and protein measurement}

The relative level of CYP2E1 and HSP90 protein in the liver was determined by Western blot analysis. The liver tissues were homogenized in ice-cold RIPA-buffer (1:3) containing $20 \mathrm{mM}$ TrisHCl, $\mathrm{pH} 7.5 ; 0.15 \mathrm{M} \mathrm{NaCl} ; 1 \mathrm{mM}$ EDTA; $1 \%$ NP-40; $1 \%$ sodium deoxycholate; $0.1 \%$ SDS and

Table 3 Comparative characteristics of the CYP2E1 and CYP2E1-ethanol spatial structures

\begin{tabular}{lcc}
\hline & CYP2E1 & CYP2E1-ethanol \\
\hline Volume $(\AA 3)$ & 41147.4 & 39364.8245 \\
Gyration radius $(\AA)$ & 22,574 & 22.671 \\
Polar surface area $(\AA 2)$ & 16936,1 & 15985.5462 \\
Surface area $(\AA 2)$ & 54400.7500 & 53120.5892 \\
RMSD - Ca $(\AA)$ & - & 0.718 \\
RMSD - all atoms $(\AA)$ & - & 1.9 \\
\hline
\end{tabular}




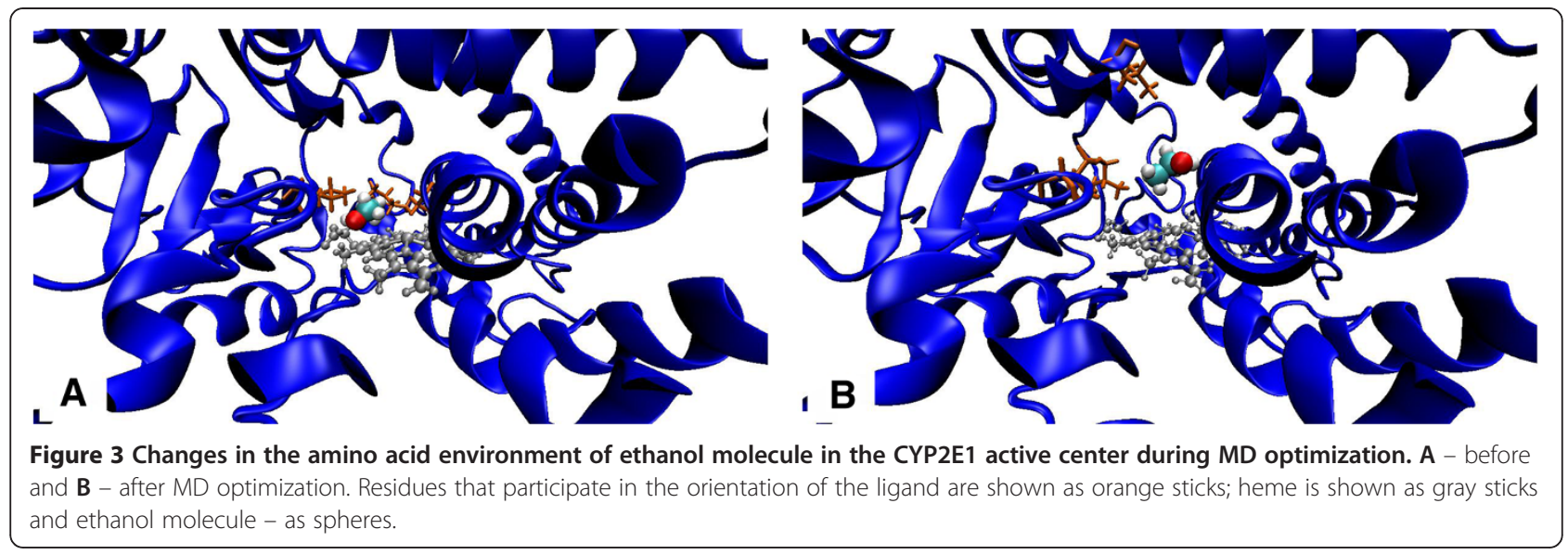

$1 \mathrm{mM}$ protease inhibitor PMSF was added to liver tissue frozen in liquid nitrogen. The extraction of proteins was carried out on ice for 45 minutes. Centrifugation was then carried out at $11000 \mathrm{~g}$. for $20 \mathrm{~min}$. at $+4^{\circ} \mathrm{C}$. The protein concentration in the supernatant was determined [16]. Proteins from the liver of each mouse (50 $\mu \mathrm{g}$ per line) were separated using $12 \%$ polyacrylamide gel with $0.1 \%$ SDS [17]. The semi-dry electrotransfer of proteins to the nitrocellulose membranes was held at $200 \mathrm{~mA}$ for $40 \mathrm{mi}$ nutes. Western blot analysis was held in the following way: nitrocellulose membranes were pre-incubated in $4 \%$ nonfat milk (Sigma, USA) in PBST-buffer, and then treated with polyclonal anti-CYP2E1 or anti-HSP90 antibodies (obtained in Rabbit in our institute earlier) diluted in 4\% nonfat milk for 1 hour at room temperature. Membranes were incubated with peroxidase-conjugated secondary anti-Rabbit antibodies (Sigma, USA) for 1 hour. The GAPD (used as control) was identified using anti-GAPD antibodies (obtained in Rabbit in our institute earlier). The treatment of membranes with secondary antibodies was followed by chemiluminescence detection according to manufacturers' instructions (Pierce). Membranes were exposed to autoradiography film (Agfa, Belgium) for 0,5 to 1 minutes. Digital images of immunoblots were analyzed using densitometric scanning analysis program Scion image 3.53.346.0 (http://www.scioncorp.com/). The level of CYP2E1 and HSP90 protein was calculated as the ratio of protein values to GAPD and presented as relative units.

\section{Statistical analysis}

Statistical analysis was performed using STATISTICA 7.0 (StatSoft, Inc. 2004, USA). Results are presented as mean \pm standard deviation (SD). Differences between groups were identified using an unpaired two-tailed distribution of Student's $\mathrm{T}$ test. $\mathrm{P}$ values $<0.05$ were considered to be statistically significant.

\section{Computational work}

Similar to the experimental data [11] we used computational model of recombinant CYP2E1 with deleted 30 a.a. at the N-terminal (membrane anchor) previously created and optimized by us [18]. The computational model of
A

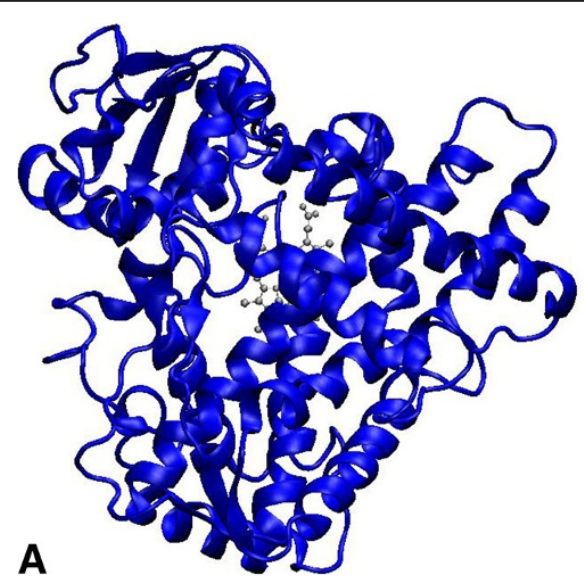

B

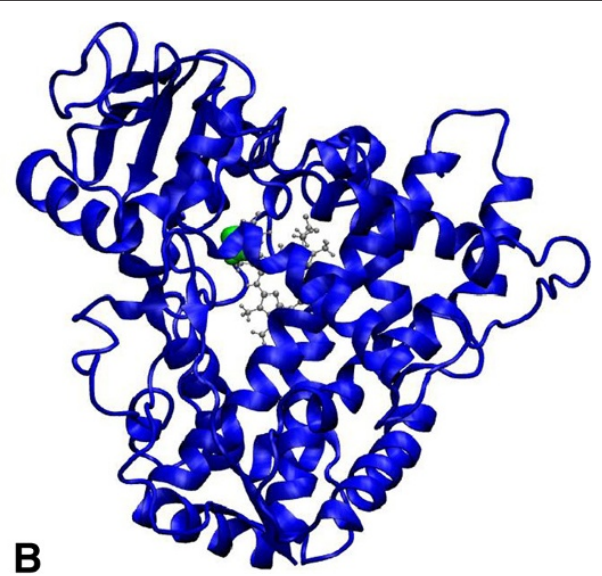

Figure 4 The comparison of spatial structures of CYP2E1 (A) and CYP2E1-ethanol (B). Heme is show as grey ball-and-stick and ethanol - as green spheres. 


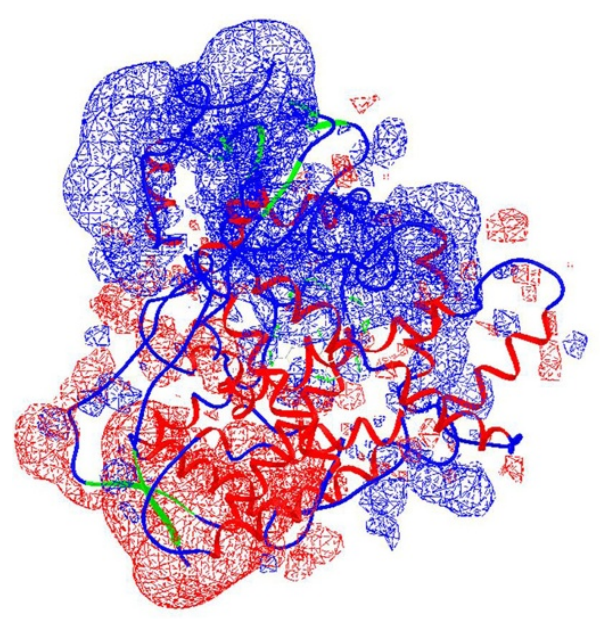

A

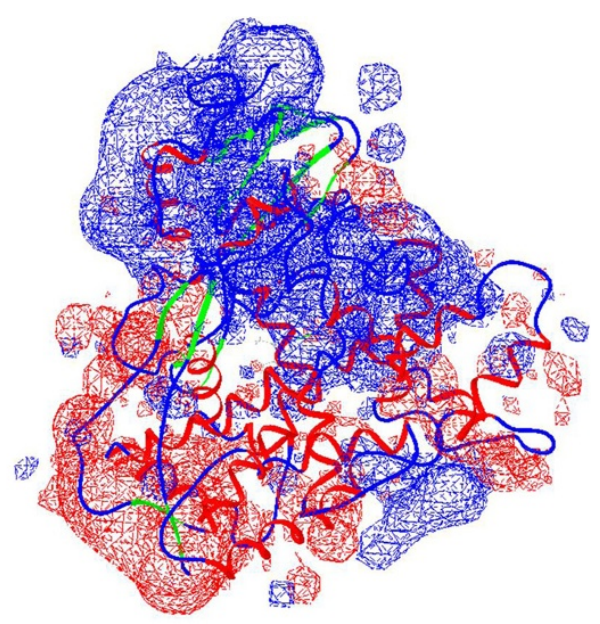

B

Figure 5 The charged surface of the CYP2E1 (A) and CYP2E1-ethanol (B). Blue shows negatively and red - positively charged protein regions.

human HSP90 was built using SWISS-MODEL web-server (http://swissmodel.expasy.org/). Protein-protein docking of CYP2E1 with HSP90 was made using HEX6.1-CUDA program with 5D FFT rotational correlation mode based on shape and electrostatics with subsequent molecular energy minimization for post processing. During this docking several CYP2E1-HSP90 complexes were obtained, whereof the most energetically favourable one (maximum energy of interaction $-\Delta G_{\text {Gibbs }}=800 \mathrm{~kJ} / \mathrm{mol}$ ) was selected. A complex of CYP2E1 with ethanol (CYP2E1-ethanol) was created and optimized using MD to investigate the influence of ethanol molecule on protein spatial structure. The docking of ethanol into the protein active site was performed using ArgusLab 4.01 program. The site of interaction with this ligand is located in the active site of the enzyme at a distance of $0,35-0,45 \mathrm{~nm}$ from the atom of heme iron and is characterized by high interaction energy $\left(\Delta \mathrm{G}_{\text {Gibbs }}=-19.72 \mathrm{~kJ} / \mathrm{mol}\right)$ and a large contact area with CYP2E1. MD simulation of the CYP2E1-ethanol molecule was performed using NAMD soft [19]. It was solvated with TIP3P water using VMD soft [20]. We used standard conditions of NVE-ensemble at the temperature of $310 \mathrm{~K}$ $\left(37^{\circ} \mathrm{C}\right)$. Simulation was conducted for 1 ns. During MD optimization some changes were shown in the ethanol molecule orientation inside the enzyme active site (amino acid environment of the ethanol molecule changed from Leu115, Ala299, Leu368 and heme to Leu210, Val364, Leu368 and heme, see Figure 3), causing minor protein structure rearrangements (Figure 4). Some characteristics of CYP2E1 spatial structure and their changes caused by ethanol are presented in Table 3. Besides, the ethanol molecule caused changes in charges on CYP2E1 surface (Figure 5). Thus large positively charged region appears in the area of entrance to the active site channel. A negatively charged area has significantly increased in the region of CYP2E1 that corresponds to the cytoplasmic domain. Protein-protein docking of the CYP2E1-ethanol with HSP90 was the same as for the complex of CYP2E1 with HSP90. The cytoplasmic domain of CYP2E1 showed the highest energy of binding with HSP90. The enzyme membrane-bound domain showed significantly lower energy of binding with HSP90 (data not shown). Also a significant reduction was shown in the interaction area and in the number of residues involved in the contact (Table 1).

\section{Competing interests}

The authors declare that they have no competing interests

\section{Authors' contributions}

KVO carried out the computational work and drafted the manuscript. MOV worked with experimental animals, carried out the immunoassays, participated in the design of the study and performed the statistical analysis. $\mathrm{CMO}$ conceived of the study, and participated in its design and coordination and helped to draft the manuscript. All authors read and approved the final manuscript.

\section{Acknowledgements}

The authors thank to the head of the laboratory of molecular mechanisms of autoimmune processes of cell signalling systems in the Institute of Molecular Biology and Genetics of the National Academy of Sciences of Ukraine, LL Sidorik for kindly providing anti-HSP90 and anti-GAPD antibodies.

Received: 10 September 2012 Accepted: 14 December 2012 Published: 17 December 2012

\section{References}

1. Lieber CS: Cytochrome P-4502E1: its physiological and pathological role. Physiol Rev 1997, 77:517-544.

2. Tanaka E, Misawa S, Terada M: Cytochrome P450 2E1: its clinical and toxicological role. J Clin Pharm Ther 2000, 25:165-175.

3. Albano $E$, Ingelman-Sundberg $M$, French SW: Hydroxyethyl radicals in ethanol hepatotoxicity. Front Biosci 1999, 4:D533-D540.

4. Cederbaum Al, Mari M, Bai J, WU D: CYP2E1-dependent toxicity and oxidative stress in HepG2 cells. Free Radic Biol Med 2001, 31:1539-1543. 
5. Wu D, Cederbaum Al: Oxidative stress mediated toxicity exerted by ethanol-inducible CYP2E1. Toxicol Appl Pharmacol 2005, 207:70-76.

6. Eliasson $E$, Ingelman-Sundberg $M$, Johansson I: Ligand-dependent maintenance of ethanol-inducible cytochrome P-450 in primary rat hepatocyte cell cultures. Biochem Biophys Res Commun 1988, 150:436-443.

7. Zanelli U, Paolicchi A, Gervasi PG, Longo V: Stabilization of cytochrome P4502E1 protein by ethanol in primary hamster hepatocyte cultures. Toxicol In Vitro 2000, 14:69-77.

8. Bardag-Gorce F, Li J, French BA, Fang C, Ingelman-Sundber M, French SW, Yuang QX: The effect of ethanol-induced cytochrome p4502E1 on the inhibition of proteasome activity by alcohol.

Biochem Biophys Res Commun 2000, 279(1):23-29.

9. Dey A, Cederbaum Al: Geldanamycin, an inhibitor of Hsp90 increases cytochrome P450 2E1 mediated toxicity in HepG2 cells through sustained activation of the p38MAPK pathway. Arch Biochem Biophys 2007, 461:275-286.

10. Goasduff T, Cederbaum Al: CYP2E1 degradation by in vitro reconstituted systems: role of the molecular chaperone hsp90. Arch Biochem Biophys 2000, 379:321-330.

11. Morishima Y, Lin HL, Hollenberg PF, Sunahara RK, Osawa Y, Pratt WB, Peng HM: Regulation of cytochrome P450 2E1 by heat shock protein 90dependent stabilization and CHIP-dependent proteasomal degradation. Biochemistry 2005, 44:16333-16340.

12. Ingelman-Sundberg $M$, Lindros $\mathrm{KO}$, Eliasson $\mathrm{E}$, Zhukov $\mathrm{A}$, Ronis MJ: Ethanolinducible cytochrome P4502E1: regulation, enzymology and molecular biology. Alcohol Alcohol Suppl 1994, 2:131-139.

13. Song BJ, Park SS, Gelboin HV, Gonzalez FJ, Veech RL: Induction of rat hepatic $\mathrm{N}$-nitrosodimethylamine demethylase by acetone is due to protein stabilization. J Biol Chem 1989, 264:3568-3572.

14. Maksymchuk OV, Bezdrobna LK, Sydoryk LL, Kysel'ova OK, Chashchyn MO: Cytochrome P450 2E1 expression in mice liver after exposure to continuous and acute gamma-radiation. Ukr Biokhim Zh 2008, 80:59-65.

15. Baraboj VA: Peroxidation and stress. St. Petersburg. Dep-tion: Science; 1992:148.

16. Bradford MM: A rapid and sensitive method for the quantitation of microgram quantities of protein utilizing the principle of protein-dye binding. Anal Biochem 1976, 72:248-254.

17. Laemmli UK: Cleavage of structural proteins during the assembly of the head of bacteriophage T4. Nature 1970, 227:680-685.

18. Kitam VO, Chashchyn MO: Computer modeling of the human cytochrome P450 2E1 complex formation. Ukr Biokhim Zh 2010, 82:94-103.

19. Phillips JC, Braun R, Wang W, Gumbart J, Tajkhorshid E, Villa E, Chipot C, Skeel RD, Kalé L, Schulten K: Scalable molecular dynamics with NAMD. J Comput Chem 2005, 26:1781-1802.

20. Humphrey W, Dalke A, Schulten K: VMD: visual molecular dynamics. J Mol Graph 1996, 14:33-38. 27-8.

doi:10.1186/1472-6807-12-33

Cite this article as: Kitam et al:: The possible mechanisms of CYP2E1 interactions with HSP90 and the influence of ethanol on them. BMC Structural Biology 2012 12:33.

\section{Submit your next manuscript to BioMed Central and take full advantage of:}

- Convenient online submission

- Thorough peer review

- No space constraints or color figure charges

- Immediate publication on acceptance

- Inclusion in PubMed, CAS, Scopus and Google Scholar

- Research which is freely available for redistribution

Submit your manuscript at www.biomedcentral.com/submit
Ciomed Central 